\title{
Narrative Writing on New Immigrant Women: Perspective on Cultural Identity and Mother-Daughter Relationship
}

\author{
Shu-Chuan Chen", Chih-Hui Fang \\ Department of Foreign Languages and Literature, Asia University, Taiwan
}

\section{A B S T R A C T}

\begin{abstract}
Three different types of narrative writings from women who have recently immigrated to Taiwan are discussed here: oral/confessional narrative, textual narrative, and documentary films. The first is the primary kind of narrative writing produced while immigrant women are still struggling with the acquirement of a new language, and relies on help from local people to deliver the new immigrants' voice. The textual narrative illustrates the mother figures in terms of madness or absence from home; emphasizing the conflict of mother-daughter relationships. The last type of narrative writing produced by newly immigrating women are the documentary films, which are shot by themselves and attempt to demonstrate the bravery of these new immigrant spouses in defending their rights. The results of this paper show that, through the narrative writings, female immigrants from Southeast Asia in Taiwan have produced a variety of issues and topics which create a link of dialogue with Taiwanese society, and which need to be understood. What is more, the process of constructing their new identity is worth discussing as it provides a new perspective on Asian ethnic and women's writing, and uncovers the need for more research into diasporic women-studied from the approach of displacement.
\end{abstract}

A R T I C L E I N F O

\author{
Paper type: \\ Research Article \\ Article history: \\ Received: 30 October 2018 \\ Revised: 11 December 2018 \\ Accepted: 11 December 2018 \\ Keywords: \\ - Narrative Writing \\ - New immigrant woemn \\ - Cultural Identity \\ - Motherhood \\ - Displacement
}

\section{Introduction}

Taiwan's marriage pattern has undergone a tremendous change since 1980s, and a huge number of female immigrants from China and Southeast Asia have started to immigrate to Taiwan. This "marriage migration", however, has only recently initiated discussion on the homeland cultures and familial identities of the female immigrant spouses. Yet the stories of these female immigrants are both demonstrated and represented through various narratives ${ }^{1}$. For example, many films, photographs and contexts delicately portray the conflicts between female immigrants and their cross-cultural families, marriages, children and even their families of origin.

The three types of narratives writing in immigration writing are: oral/confessional narratives, textual narratives, and documentary films ${ }^{2}$. The great value of the narrative writings from immigrant female writers is to provide a dynamic of immigration, especially as the issue of the gender cannot be excluded from the phenomena of modern diaspora, as Berger (2004) states in her book. Using narrative writing to relate the stories

\footnotetext{
* Corresponding Author. This paper is a Ministry of Science and Technology in Taiwan (MOST) sponsored project numbered 106-2410-H-468-014-. E-mail Addresses: csc71@asia.edu.tw (S. C. Chen), ch.fang@asia.edu.tw (C. H. Fang).

${ }^{1}$ The immigrant spouses are regarded as "cultural carriers, practitioners and deliverers" and what new female practitioners and deliverers" and what new female immigrants from transnational marriage bring from their country of origin is worth discussing and surveying. As Li (2012) declares; "culture reproduction" is also the phenomena of their gradual adjustments in the new environment.

2 These three types of narrative writing are categorized by the authors of the paper according to the collected materials of Southeast Asia immigrant spouses in Taiwan.
} 
is also a method of therapy connecting personal experiences, “... locating the problem in history and in a storyline, and tracing the effects of the problem on the person's life and relationships" (Russell \& Carey 2013). Firstly, the female immigrants describe their stories verbally by means of their own language and then either translate them into Chinese, or write them down in simple Chinese. For example, through first-person monologues, a Taiwanese female artist, Hou (2005-2009) depicts seven female immigrant spouses in her threeepisode work: Look toward the Other Side: Song of Asian Foreign Brides in Taiwan 2005-2009. These episodes explore the issue of spouses' self-identities while living in an exotic place. The textual narrative is the second type of immigrant writing and it tends to focus on the mother-daughter relationships. Examples here are Wu's (2010) three short stories in Moving Skirts, which is discussed below. The textual narrative usually illustrates the mother figure with madness, aphasia ${ }^{3}$, or absence from home. All mothers are silent-they have no voice. Finally, Nguyen Kim Hong's two documentary films, Out/Marriage and Let's not be Afraid, indicate that women not only play the role of mothers, wives, and daughters-in-law, but also as defenders who endeavor to protect their rights.

This paper explores the issues of Taiwanese immigrants from Southeast Asia in terms of: (1) self-awareness and cultural identity; (2) motherhood and mother-daughter relationships; (3) narrative writing. It not only aims to provide a new perspective for Asian ethics and women's writing, but to establish a milestone through the research of displacement and theories of motherhood, for the research possibilities concerning diasporic women.

\section{Research Methods}

This paper will probe the issues of new immigrant spouses in Taiwan with the research methods of Minh-ha Trinh's theory of displacement, and the theories of motherhood from Firestone (1970), Oakley (1985), and Rich (1977).

\subsection{Minh-ha Trinh's theory of displacement}

When Trinh (1989) attempts to define the meaning of writing, especially in regard to women writers, she states that 'the writer is necessarily either God or Priest' (p.29) to question the Priest-God scheme designed by ancient systems. Therefore, writing ensures the identity of women, and according to Trinh's concerns, a woman who is categorized as being from a minority, in particular, should identify herself with 'infinite layers'. She further delivers the statement that whenever the authority tries to define the meaning of "the other", the subjectivity of the other, I, will not be considered just "I", but also can be you and me, both are involved. In this way, Trihn attempts to refer that no one can be outsidered as the outsider since the hegemony is trying categorize the minority as the other as a whole. "You and I are close, we interwine; you may stand on the other side of the hill once in a while, but you may also be me, while remaining what you are and what I am not (p.90).

One of the practical methods of narrating a woman's story is for the woman to document herself, to film herself, and thus make self-identity possible. The camera has been said to have been dominated by western society since it was invented. To subvert the situation of being gazed at, it is crucial that the woman herself takes up the camera. According to Trinh (1990), cinema is an ideal medium for documentary the truth and also can be functioned well on the market. The documentary dares to confront the problem, to reveal the hidden parts, to record what people struggle for. With the help of the camera/documentary, the narration and the images represent a whole new representation of a woman's story. Trinh emphasizes that the new technique of cameras/facilities can bring a different impact to the representation of women, which is not possible when only applying textual theories or practices. Therefore, to spread the narrations/stories of the minorities, especially these immigrant spouses, the strategy here is, as Leslie Marmon Silko states; "It will take a long time, but the story must be told. There must not be any lies", as Trinh (1989) referred to in the chapter of "Granma's Story". The truth will be revealed and the story/memory will be a part of the history. A story-teller is a creator and her mission is more than just being a story-teller but "being a great mother, a teacher, a poetess, a warrior, a

\footnotetext{
${ }^{3}$ According to The National Aphasia Association, the definitions of aphasia from a medical aspect is that "Aphasia is an impairment of language, affecting the production or comprehension of speech and the ability to read or write." And if referring aphasia to language production, "Aphasia is a condition in which previously normal and literate users of a language suffer a disruption in the operation of language processes, including language production...Aphasic speakers may exhibit marked reductions in fluency, may have enormous difficulty producing words to express meaning, may produce fragmented utterances interrupted by numerous pauses, and may produce words that do not express what they intended to say" Berndt (2012). However, this paper puts more emphasis on cultural and literal concepts as a studying background which indicates that immigrant females face the challenge of new environments, new languages, and new identities which lead to their incability to produce utterances
} 
musician, a historian, a fairy, a witch, a healer and a protectress". No matter whether the story is beautiful or violent, or with an end or not; borrowing from the idea of Marmon Silko, Trinh (1989) explains that the storyteller possesses a duty of survival and legacy of a tribe. To demonstrate the power of telling story, the storyteller will embed multiple stories in which story and life merge which will help the audience/the tribal people understand the important meanings from the narratives.

Continuing her strategy of displacement, Trinh (2010) put forth more on how a global phenomenon can become material to be presented/represented by a productive system. In her Elsewhere, Within Here: Immigration, Refugeeism and the Boundary Event, she considers that displacement and forced migration are rooted in complex social, political, and historical contexts. The borders and boundaries come from both the physical and the imagined in our everyday lives. Again, the strategy is to find the intervals between various spaces that can interrupt boundaries and discursive dichotomies ${ }^{4}$. Speaking is necessary to reconstruct identity.

Trinh (1991) considers that "identity can very well speak its plurality without suppressing its singularity, heterologies of knowledge give all practices of the self a festively vertiginous dimension". The immigrant women should not limit themselves to the margins but utilize the position of being in the margin, from which Trinh (1991) suggests that: "If without the margin, there is no center, no heart...The center itself is a marginal". She refers the strategy as, "a woman narrates a displacement as she relentlessly shutters between the center and the margin...marginal by imposition, by choice, by necessity. The struggle is always multiple and transversal.

According to the strategies of placement mention above, the stereotype of immigrant females can be manipulated by reconstructing the identification of the individual, especially when Taiwanese society often portrays these "Southeast-Asian immigrant wives as problem-makers" (Wang, 2012).

\subsection{Motherhood from feminists' aspects}

Women are often regarded as tools of reproduction. It was not until the feminist movement, at the beginning of eighteenth century, that the issue of motherhood was debated. Before women's liberation, motherhood was considered to be an individual problem rather than a social construction. Despite the admittance of the existence of heterosexual hegemony and hierarchy leading women to motherhood it was, and still is, essential to normalize the paradigm of roles between men and women, including viewing motherhood as a duty for women.

There are two attitudes to motherhood: one regards motherhood as depreciating women's status; the other promotes motherhood as a common experience among women. Since the eighteenth century, the issue of motherhood has been discussed by feminists such as Mary Wollstonecraft (2018)5. Positioning "woman" within debates about human rights and economic liberation is liberal feminism. Furthermore, it encourages women to go out from the household and work in the public sphere. However, men rarely share the household duties, so women often suffer a double burden in dealing with both public and domestic matters. In the 1960s, a radical view towards motherhood began to emerge. Women's physical reproduction, as far as radical feminism was concerned, was the crucial element in women's inferiority. To eliminate inequality, women should give up motherhood, with artificial reproduction being regarded as the best way of doing so.

Oakley (1985) posits three hidden sisterhoods amongst women: co-operation between women; the bonds between mothers and daughters; and the sisterhood in lesbianism. She does not deny the intimately emotional ties that motherhood may bring, and argues that this tendency leads women to be hostile towards men.

The concept of motherhood, for Adrienne Rich, can be divided into the "experience of mothering" and the "institution of motherhood." Throughout the book, Rich (1977) tries to distinguish between meanings of motherhood. One is the potential relationship of reproduction and to children, and the otrher is the institution. The latter aims to ensure that women's potential should remain under male control. This institution has been a keystone of the most diverse social and political systems.

The 'experience of mothering' refers to what the experience of motherhood brings to women, and the 'institution of motherhood' refers to that experience under the construction of patriarchy. Women have, "been literally massacred on the site of motherhood" (Rich, 1977). Under patriarchy, women do not have complete power over educating or controlling their own children as it is the father figure who is dominant in the family. If children do not behave properly, the father figure assigns blame to the mother. Yet, Rich (1977), unlike

\footnotetext{
${ }^{4}$ See the book review from Delila Omerbasic (2013) in Journal of Refugee Studies, 26 (2), 310-311.

${ }^{5}$ For instance, Mary Wollstonecraft (1759-1797), in A Vindication of the Right of Women, explains the differentiation of men and women (women as emotional and men as rational) as the result of social constructions. She strongly believed that women were capable of becoming rational and independent if they received enough education. Wollstonecraft, however, still advocated the obligation of motherhood: better education allowing women to become responsible mothers and housewives.
} 
Firestone, does not wish to abolish the biological experience of motherhood, because it is the patriarchal system which degrades women's position, not reproduction.

Chodorow (1978) maintains that both boys and girls' personalities are formed by their attachment to their mothers. According to Freud (1990), boys in their Oedipal stage become masculine for the sake of identifying with their fathers. Therefore, a normal masculine psychology is developed, which places women in the category of "other." In contrast, the relationship between mother and daughter is continuous, and no break in the girl's identification with her mother is required. In the process of consolidating the masculine identification with the father figure in the boy, the girl's attachment remains with her mother.

For Chodorow, it is essential for the girl to have a father figure as the primary object as she thus does not actually turn from her mother to her father, as Freud (1990) argued. Feminists emphasize the significance of motherhood and daughterhood, allowing for women's solidarity in the patriarchal system, as well as in Freud's (1990) heterosexual bias.

Thus, it is convincingly argued that Freud's (1990) notion of 'penis envy' is irrelevant for women. The concept of the female Oedipus Complex, for Chodorow, is not merely the transference from mother to father, but rather the significance of girls' 'external' and 'internal' relations toward their mothers. Through the process of this transformation, women are able to achieve "self-definition and personality which is not characteristic of masculine self-definition or personality" (Chodorow, 1978).

\section{Results and Discussion}

\subsection{Oral/confessional narrative: Toward the Other Side: Song of Asian Foreign Brides in Taiwan.}

Due to limited language ability, the new immigrant women are not able to speak fluently when narrating their stories in Chinese. Taiwan female artist Lulu Shur-tzy Hou's series of works Toward the Other Side: Song of Asian Foreign Brides in Taiwan 2005-2009 is presented in the way of being a spokesperson for the unspoken. It is the artist who explores the immigrant women from the view points of seven Vietnamese spouses (who used to be called foreign brides) and their Vietnamese native family images by first-person monologue. Hou's original idea is to take simple but realistic family photos from different angles; she is trying to 'help' the immigrant spouses to escape being labeled as 'others' and reconstruct the identity of their new life in Taiwan. Through self-consciousness and cognition, Hou tries to show the cultural and class differences in the image of Taiwan-Vietnamese marriage and leads the audience to acknowledge and ponder the issues of these new Taiwanese residents. As Huang (2010) points out that these immigrant women leave their families and home country, and re-establish a new identity. However, people in Taiwan usually stereotype them as the tool of reproduction and production. The sense of the discrimination ignores their devotion to their home, their family, and their nation(s). "We not only reject them, but also reject the culture of our children's mother".

In such a predicament, Hou (2005-2009) the artist, from the feminist's point of view, considers herself as a woman who is a denial of husband, home and nation, realizing these immigrant women are struggling to deal with a different culture in Taiwan. The artist is gradually aware of this difference of culture and class and, as Huang (2010) states that Hou is not making a critical statement but trying to reveal the scattered fragments of the panic and the fear from the view of these immigrant women. She regards her photography aims to help these immigrant sppuses to adapt the new circumstances and expects to build a mutual understanding from the public. Hou's (2005-2009) photography is not a documentary recounting; therefore, she does not apply a sensational or provocative record of life. From Huang's (2010) analysis, Hou just invites the women to step out of the family quietly, photographing them in their own home. Each image can be represented as a fragment of the flow of globalization. Through the dialogue and content between the artist and the immigrant spouse being represented by the re-coloration of the photograph, which is arranged alongside and in contrast to the original. As we can see that these are pictures of opportunities, happiness and pain which juxtapose the portrait of the dream and the artist's feelings for the woman's story. So, by re-tinting the photograph, the objects of the photography can be read and understood in terms of what is hidden in their deepest minds.

In this series of works it is immigrant spouses who dominate the situation and dialogue; the artist is not the master. In order to delineate these marital relations, Hou interviews the immigrant spouses to record their feelings with the purpose of helping them to write their biographies. They are a silent group who, after they settle down in Taiwan, cannot adequately express themselves in their new language (Fig. 1). Hou's method is to apply these immigrant women's biographic oral records to the photo image. It seems that the artist provides 
a conduit for a collective atonement for the unfair treatment Taiwanese society has imposed on these immigrant women ever since they arrived in Taiwan.

This exhibition presents the faces of the immigrant spouses for the audience to contemplate. And because of the positioning of the photographs, the immigrant spouses seem to be facing the audience in a dialogue in which one appears to be able to read their inner confession ${ }^{6}$. Through the images Hou aims to show the presence of immigrant spouses as well as Taiwan-Vietnam intricate marital relationships. They are the people to be recorded, but they are also willing to share the experience through narrations and images. The exhibition raises concerns from many people in Taiwan, which is very important as Hou and the immigrant brides accomplish a difficult and challenging task. The situational and delicate design of the exhibition and storyline of the two homes (the native and the migrant ones) is the main theme. For example, it shows an immigrant spouse from Vietnam who lives in Pingtung County (Taiwan) with her husband who tortures her physically and mentally; or a mother who looks forward to seeing her children having a bright future in Taiwan (Fig. 2 \& Fig. 3). People read a fragment of a story from a real family, or glimpse a moment of their inner feelings as the artist puts together a collective, but different, Asian female life experience directly in front of the audience. Hsieh (2014) concludes that, mediated by the artist, those marginalized others enter the field of artworks through text and images, "Under Hou's leading, viewers can take a serious look at the problems caused by the cross-border movement, and the 'others' have been given the opportunity to re-express themselves". Furthermore, Wang (2012) considers that a documentary film is a medium of record which can represent the images of the new immigrant females and depict their stories of struggling/striving through the means of narrative.
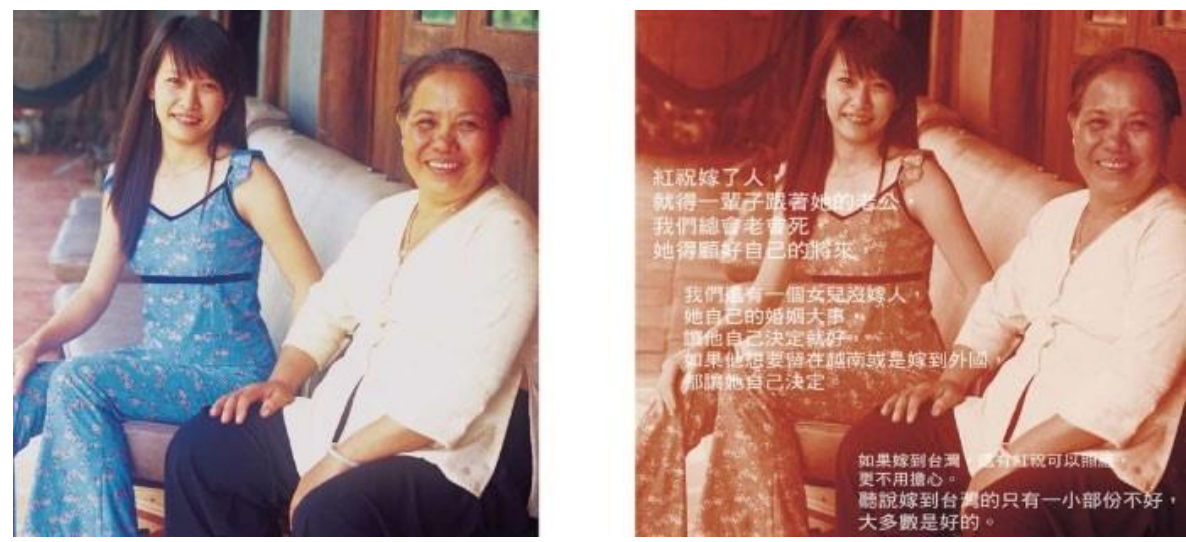

Fig. 1. Lulu Shur-tzy Hou, Look toward the other side-Song of Asian Foreign Brides in Taiwan III
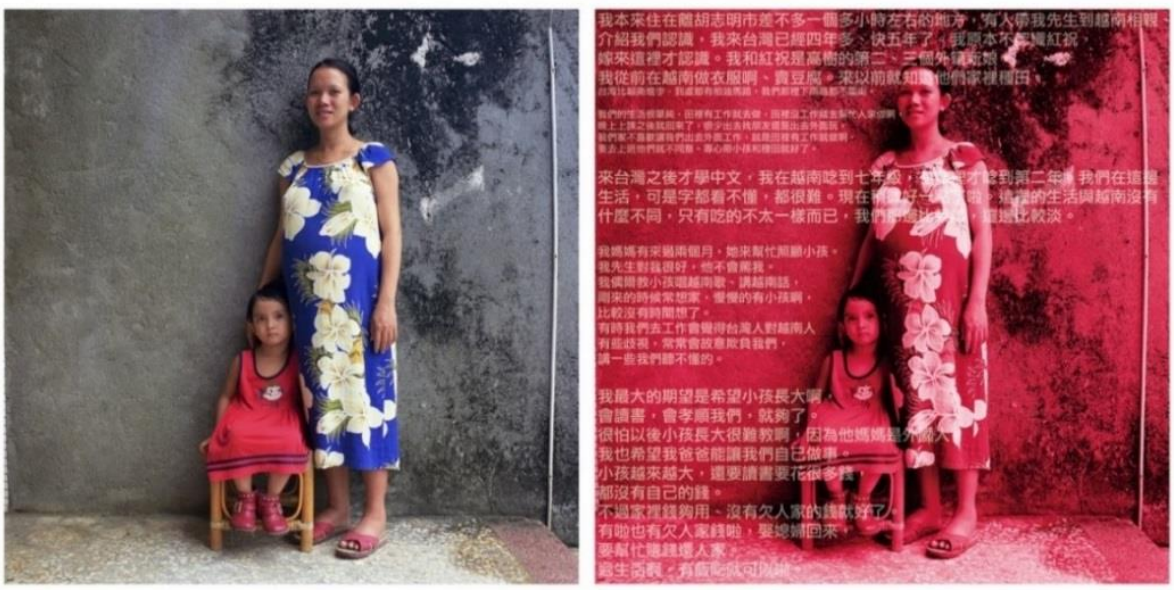

Fig. 2. Lulu Shur-tzy Hou, Look toward the other side-Song of Asian Foreign Brides in Taiwan III

\footnotetext{
${ }^{6}$ To see the exhibition location and the interview with the artist, link to <https://www.youtube.com/watch?v=_AxoGr4CXYg>
} 


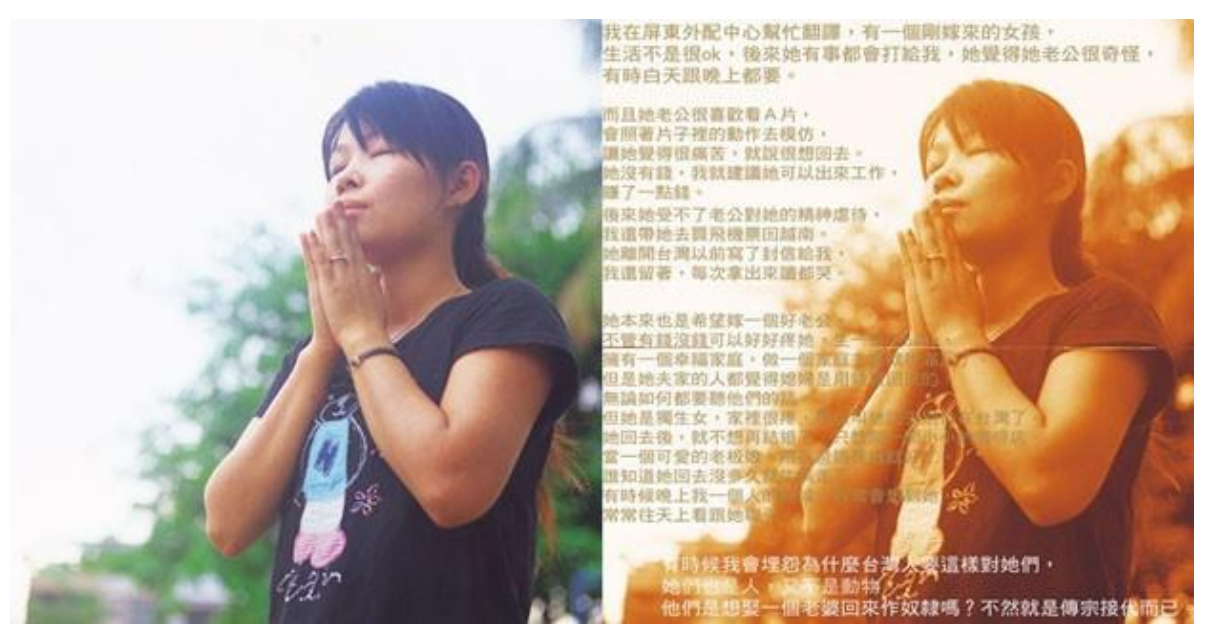

Fig. 3. Lulu Shur-tzy Hou, Look toward the other side-Song of Asian Foreign Brides in Taiwan III

\subsection{Textual narrative: The Moving Skirt}

Peipei $\mathrm{Wu}$ tends to view the position of new immigrants as a constructed object. Wu does actually describe the unequal positions of some new immigrant women, however, due to social restrictions, some female immigrants are voiceless (Chang, 2014). When Wu (2010) was studying as a graduate student, she interviewed families and collected their different experiences, such as the relationships between foreign spouses and migrant workers. Some became wives and caretakers for men with physical disabilities, others became machines for reproduction, and some became prostitutes controlled by people-smuggling gangs. There are eleven short stories in The Moving Skirt including the stories of immigrants from Vietnam, Indonesia, China, and the Philippines. These new residents, from her descriptions, have something in common in that although they are all in 'weak' and unbearable situations, she always provides them with a happy ending. Originally, they are away from home or voiceless, then they return to the 'normal track' as standard mothers, wives and daughters-in-law. Take 'Glass. Half. Daughter' for instance, it portrays the contrary relationships between the immigrant mother from Vietnam and her daughter. In the story, the immigrant mother who had been engaged in sex work in her hometown suffered from discrimination after she came to Taiwan. Every relative on her husband's side despised her previous work, which led her to suffer a mental illness. Later she gave birth to a daughter, and her husband's family named the baby 'Jing He.' The Vietnamese mother did not like the name 'Jing He', instead she called her 'Mei Lian,' which is the same name as the mother's sister in Vietnam and also a traditional Vietnamese name. However, the daughter, Mei Lian hated this Vietnamese name very much, saying that her name is Yu He. Under inappropriate education from her mother, Mei Lian eventually became mentally abnormal too. Fortunately, she was adopted and counseled by an elementary teacher and then she was later admitted to a Girl's Senior High School. Jing He's mother was gradually getting better after receiving medical treatment and finally accepted her daughter by calling her Jing He. The mother plays the role of a voiceless woman, except for calling her daughter, Mei Lian. However, the Vietnamese name 'Mei Lian' also implies that the mother's role is actually sub-cultural and unacceptable in Taiwanese society. In contrast, the Taiwanese name 'Jing He' represents a patriarchal and dominant culture. The story Kara Duo also depicts the mother-daughter relationship. A Vietnamese woman married a Taiwanese man and then ran a karaoke business, and also ran an illegal sex-trade business behind the store. Even though conducting an illegal business, the Vietnamese mother was very strict with her daughter, not allowing her to follow in her steps. However, her daughter insisted on becoming a prostitute. Wu (2010) portrays the helplessness of immigrant women carefully: the helplessness in facing their native country and family, the weak and conventional husband in Taiwan, and the cultural differences in raising children. Finally, the article ' ‡女’ (prostitute) describes a son, Zhou Mulin, whose mother left home, and who was encouraged to learn drawing by a teacher. He achieved a good grade in a competition, and received the approval of his peers. All the mothers mentioned above face mental disorder, aphasia, as well as abandoning their children. 


\subsection{Documentary films: Out/Marriage and TASAT}

Two cases are studied here for the third type of narrative writing. Nguyen Kim Hong is a new immigrant from Vietnam, and she became a documentary director in 2009. Through her divorce, she has become brave enough to tell the story of her and other sisters with the lens ${ }^{7}$. Her documentary Out/ Marriage was a finalist in the 2013 Taipei Film Festival and the South Film Festival best documentary ${ }^{8}$. The film records four foreign spouses in Taiwan who went through a broken marriage. They each face a different family situation, and finally embark on a voluntary or involuntary divorce. The three main characters in the film Out/Marriage are: Magnolia, Golden Bell, and A-Shih. Like all new immigrant sisters, they once embraced the dream of pursuing happiness in Taiwan, but failed to continue their marriage ${ }^{9}$. However, their life in Taiwan has not ended even though their marriage has. How do they choose the next step in life? And what education they can offer to their children who were born in Taiwan? What kind of life and educational problems will the children face after the breakup of their parents' transnational marriages? The solutions are not easy to find as life goes on and people are often overwhelmed by reality. However, Hong's documentary conducts narratives from the aspects and views of these three immigrant spouses, whose spirit of striving to survive in an indifferent society is encouraging. What is more, more issues will be brought up: Can society be changed? Can the immigrant spouses be treated fairly? According to $\mathrm{Ke}$ (2015), self-filming is significant in that it can help these oppressed women be more selfconfident and be positive to search for the construction for their subjectivity. These Southeast Asian immigrant women consider themselves are on a journey of self-revelation by a camcorder.

The second documentary film, Let's Not Be Afraid, depicts immigrant spouses standing up to protect their rights ${ }^{10}$. The immigrant spouses are aware of the need to be united and fight for their rights together. Therefore, an organization-TASAT: Trans Asia Sisters Association, Taiwan, has been set up to provide a wide range of information and support for the sisters. They are willing to come forward to challenge their exclusion from laws and regulations, and to fight for identity and rights, but how can they stand up to fight for the laws and regulations of the new immigrant sisters who do not want others to call them 'foreign bride' while they are learning a new language, educating their children and taking care of their families? How did they evolve from a silent group to an immigrant movement? Influenced by the idea of imagined community, by Benedict Anderson, nation is thought of as a socially constructed community, plus, the media help create imagined communities through the use of images. It is the media that bring these immigrant spouses together and create a solid community. There is no geographical boundary or limit and the sisters share highly relevant connections. TASAT is seeking more interdisciplinary collaborations and there are more projects of empowerment for the sisterhood being developed (Lin et. al., 2005). Therefore, TASAT starts to voice the sisters' needs and feelings. To record their stories through their true voices, that is 'singing it out loud' and they have made an album of a collection of songs of their own creation, and in a combination of different South-East Asian languages. One good example here is the poetic song 'Chakchenh'11. The first word of the poem 'Chakchenh' has the meaning 'leaving' in Khmer, but it is much like 'rooted' in Chinese. The coincidence of the language is like a prophecy that the sisters 'leave' their hometown across the sea to come to Taiwan and 'take root' at the end of this journey.

Departure, taking root

I left the hometown I loved

Feeling empty and unreal. I have nowhere to go.

Feeling panicked, lonely and helpless.

Bursts of pressure cause me suffocation pain.

My hometown evokes a search for what I've lost.

The uncertain self is about to fall.

I'm anchored and rooted on this island.

Search for a path that suits me.

No identity papers can be found in the naked flesh and blood.

All I bear is a seed and myself.

Drifting in the cracks between borders.

\footnotetext{
7 The immigrant spouses started to call each other 'sisters' in order to enhance their connections and relationships.

${ }^{8}$ She won the Southern Film Festival-Southern Newcomer Award in 2014 and the new documentary Lovely Stranger won the Golden Ear Award.

${ }^{9}$ To see the trailer, visit <https://www.youtube.com/watch?v=CmqSH23VmlU>

${ }^{10}$ To see the official trailer, visit <https://www.youtube.com/watch?v=N69j083_OSO>

${ }^{11}$ To see the music video, visit <https://www.youtube.com/watch?v=T_cJnCB_BRE>
} 
My hometown evokes a search for what I've lost.

The uncertain self

Bursts of pressure cause me suffocation pain.

No identity papers can be found.

All I bear is a seed and myself.

Drifting in the cracks between borders.

Flickering, darkening and slowly seeing the light.

Flickering, darkening and slowly seeing the light...

The other example is that the sisters adapt a famous Thailand song, 'Water Lamp Song' to 'Loi grà tong' ('Ode to Sisters'), describing the TASAT members as sisters in Taiwan, where they meet, love each other, and provide mutual support. The song expresses the idea that the sisters will be close to each other, grow together here, and thrive together. This song is also the soundtrack of Let's not be Afraid.

\section{Conclusion and Suggestions}

Narrative writing is an expressive method of giving the readers or viewers a new vision of these diasporic people. The objects portrayed can be various, such as mentioned in Chen (2017), "The poetic titles of these photographs deliver a message of deconstruction, fluidity, displacement and disruption" when referring to the photography of Zarina Bhimji which tries to recede/reduce the usage of language and people's portraits. However, the writings of the new immigrant spouses in Taiwan tend to have a closer observation of, and participation with, the real lives of the people themselves, and their stories from within. Wang (2010) indicates that

In their transnational marriages associated with commodification, and in the patriarchal family lineage system prevalent in Taiwanese society the common assumption indicating that immigrant wives are 'incompetent' and 'powerless' mothers has ignored the agency exertion of these women and simplified their strong tie with their children.

This could be seen as the new identity of the new immigrant spouses. Standing on the new land/territory and trying to be rooted and connected to their new lives with their family and the people who share the same faith and dream.

Viewing it as the main oppression of women, radical feminism is concerned with the patriarchal system. Feminists such as Firestone (1970), Oakley (1985), and Rich (1977), have different perspectives on motherhood. For instance, Firestone subverts the paradigm of biological reproduction, and views an androgynous society as the best way to eliminate the sexual/gender divergence. In The Dialectic of Sex ${ }^{12}$, she rejects motherhood, and believes that biological reproduction is the source of unequal power relations between men and women. Biological motherhood is, in fact, the hindrance limiting women in the public sphere. Oakley (1985) and Rich (1977) trace the importance of the pre-oedipal period in order to reinforce the relationship between motherhood, daughterhood, and sisterhood.

For Chodorow, motherhood in the pre-oedipal stage is a kind of 'prolonged symbiosis,' and it is because daughter and mother are both female that the sense of gender and self in daughter is always linked with the mother. Furthermore, Chodorow and other feminists utilize the insight of object-relation as the theory through which to analyze different experiences in boys' and girls' development. The object-relation explains the progress by which children become adults. Gardiner (1985) claims that the object-relation: "stresses the construction of the self in social relationships rather than through instinctual drives. In this terminology, 'objects' include everything that the self perceives as not itself. That is, the maternal object is not the mother but the child's mental representation of its mother"13.

To sum up, through the narrative writings, female immigrants from Southeast Asia in Taiwan have produced a variety of issues and topics which create a link of dialogue with Taiwanese society, and which need to be seen, be read and be understood. The writings are going on and the stories of their immigrant experiences/histories also help to inspire the people who concern the issues of immigration and gender.

\footnotetext{
${ }^{12}$ Firestone, Shulamith (1970). The dialectic of sex. New York: Bantam Books Press.

${ }^{13}$ Gardiner, Judith Kegan (1985). Mind mother: psychoanalysis and feminism. In Gayle Greene \& Coppélia Kahn (Eds), Making a difference: feminist literary criticism (p. 130). London and New York: Routledge Press.
} 


\section{References}

Berger, R. (2004). Immigrant women tell their stories. New York: Haworth Press.

Chang, C.-H. (2014). The formation of new female immigrants images in Taiwanese novels. Taiwan's Studies in Literature and History, $\operatorname{VIII}(6), 9-27$.

Chen, S.-C. (2017). Diasporic landscape of women's poiesis: Zarina Bhimji's photography love. Journal of Jin-Wen Institute of Technology, XXVII(2), 105-124.

Chodorow, N. (1978). The Reproduction of mothering: Psychoanalysis and the sociology of gender. London: University of California Press.

Firestone, S. (1970). The Dialectic of Sex. New York: Bantam Books Press.

Freud, S. (1990). Totem and Taboo. New York: W.W. Norton Company Press.

Gardiner, J. K. (1985). Mind mother: psychoanalysis and feminism, making a difference: Feminist literary criticism. London: Routledge Press.

Hou, L. S.-t. (2005-2009). Look toward the Other Side: Song of Asian Foreign Brides in Taiwan 2005-2009 [photograph]. Artist Collection.

Hsieh, W.-J. (2014). Voices of the silenced: Shur-tzy Hou's song of asian foreign brides in Taiwan (20052009). Taipei: National Taipei University of Education.

Huang, S. Q. (2010). Women without husbands/homes/nations: dialogue between feminists and others. Retrieved from http://www.south.org.tw: http://www.south.org.tw/?p=1033

Ke, W.-C. (2015). From oppression to liberation: The anti-representation and praxis of self-filming among female immigrants from Southeast Asia. Taiwan Journal of Sociology of Education, XV(1), 89-131.

Lin, C.-j., Wang, C.-Y., \& Wu, S.-w. (2005). Organizing immigrant women: an interdisciplinary collaborative project. The 2nd Symposium on Border Crossing and Displacement at Shih Hsin University. Retrieved from http://chinju.dlearn.kmu.edu.tw/publication/3-2.pdf

Oakley, A. (1985). Subject women. London: Fontana Press.

Rich, A. (1977). Of woman born: Motherhood as experience and institution. London: Virago Press.

Russell, S., \& Carey, M. (2013). Feminism, therapy and narrative ideas: exploring some not-so-commonly asked questions. Retrieved from http://www.narrativeapproaches.com/feminism-therapy-andnarrative-ideas-exploring-some-not-so-commonly-asked-questions/

Trinh, T. M.-h. (1989). Women, native, other: Writing postcoloniality and feminism. Bloomington: Indiana UP.

Trinh, T. M.-h. (1990). Documentary Is/Not a Name. 76-98.

Trinh, T. M.-h. (1991). When the moon waxes red: Representation, gender, and cultural politics. New York and London: Routledge.

Trinh, T. M.-h. (2010). Elsewhere, within here: Immigration, refugeeism and the boundary event. New York: Routledge.

Wang, W. (2012). The Diaspora aesthetic in the documentary films on Taiwan's foreign brides: "Look toward the Other Side: Song of Asian Foreign Brides in Taiwan-Lulu Shur-tzy Hou", "My Important Wife" and "My Rehearsing Marriage: as examples". Journal of National Taiwan College of Arts, VII(1), $161-187$.

Wang, Y.-H. (2010). Being a mother in a foreign land: Perspectives of immigrant wives on mothering experience in Taiwan. Taiwan Journal of Southeast Asia Studies, VII(1), 3-40.

Wang, Y.-H. (2012). Ambiguous belonging, strategic negotiation-national identification of Southeast-Asian immigrant wives in Taiwan. Taiwan: A Radical Quarterly in Social Studies, LVVVIX, 83-125.

Wollstonecraft, M. (2018). A Vindication of the rights of woman. Frankfurt: Digireads Publishing.

Wu, P. (2010). The moving skirt. Taipei: Aquarius Press. 